\title{
Uma abordagem da história da energia nuclear para a formação de professores de física ${ }^{1}$
}

\section{An approach to the history of nuclear power for the training of physics teachers}

\author{
WINSTON GOMES SCHMIEDECKE \\ Instituto Federal de Educação, Ciência e Tecnologia de São Paulo | IFSP
}

PAULO ALVES PORTO

Universidade de São Paulo | USP

RESUMO O ensino de Física Moderna e Contemporânea tem sido objeto de investigações por pesquisadores da área de ensino de física. Dentre seus conteúdos, este trabalho aborda a Física Nuclear, com base em seu potencial para promover reflexões sobre questões de relevância sócio-histórico-cultural no mundo atual. Nesse sentido, realizamos uma investigação com professores em formação acerca de seus conhecimentos quanto ao histórico da energia nuclear. Um breve questionário respondido pelos licenciandos sinaliza para a ineficácia do trabalho histórico atualmente desenvolvido pelas disciplinas abordando essa temática nas licenciaturas, em geral focadas somente na apresentação de aspectos teóricos, experimentais e tecnológicos. Com base nas respostas produzidas pelos alunos, e tendo como referencial a moderna historiografia da ciência, apresentamos uma proposta para o ensino a respeito da energia nuclear alternativa à habitualmente adotada nos cursos de licenciatura em Física. Os resultados da aplicação dessa proposta indicam seu potencial para promover discussões sobre a ciência entre os futuros docentes, oferecendo-lhes uma visão mais crítica acerca do empreendimento científico, em alinhamento com os atuais ideais da formação a ser desenvolvida na escola básica.

Palavras-chave formação de professores de física - física moderna e contemporânea - energia nuclear.

\begin{abstract}
The teaching of Modern and Contemporary Physics (MCP) has been investigated by researchers in physics education. Among the several contents covered by MCP, this paper emphasizes Nuclear Physics, due to its potential to promote reflections on issues of socio-historical and cultural relevance in contemporary world. An investigation with physics student-teachers about their knowledge regarding the history of nuclear power was conducted. A brief questionnaire answered by undergraduates signals to the ineffectiveness of the historical work currently undertaken by the disciplines addressing this topic in the undergraduate level, generally focused only on the presentation of theoretical, experimental and technological aspects. Based on these answers, and taking as reference the modern historiography of science, we present an approach to the teaching about nuclear power which is not usually adopted in undergraduate courses in physics. Results from such approach indicate its significance and ability to support discussions about science with future teachers, providing them with a more critical view about scientific enterprise, in alignment with current goals for elementary school education.
\end{abstract}

Keywords physics teachers training - modern and contemporary physics - nuclear power. 


\section{Introdução}

Em particular nas últimas duas décadas, pode-se observar no Brasil uma forte tendência em favor da introdução de conteúdos da Física Moderna e Contemporânea (FMC) na escola básica, justificada em grande parte, mas não somente, pelos avanços tecnológicos proporcionados pelos conhecimentos desenvolvidos no âmbito desse vasto ramo da física. Tal tendência é corroborada por diversos trabalhos acadêmicos ${ }^{2}$ e por documentos oficiais ${ }^{3}$ que regem a educação no país, os quais também destacam essa necessidade.

0 Guia de Livros Didáticos que dá suporte à última versão consolidada do Programa Nacional do Livro Didático (PNLD), ao estabelecer seus critérios visando à aprovação das obras de Física, destaca, entre outros elementos, ser essencial que a obra aborde, "sempre de forma adequada e pertinente, considerando os diversos estudos presentes na literatura atual da área, tópicos usualmente classificados como de Física Moderna e Contemporânea e que sejam considerados importantes ou mesmo imprescindíveis para o exercício da cidadania ativa, crítica e transformadora, bem como para a inserção ativa, crítica e transformadora no mundo do trabalho."4

Visando oferecer subsídios para essa aproximação, a História da Ciência apresenta-se como um campo do conhecimento provedor de critérios, estratégias e recursos voltados ao oferecimento de uma educação científica mais humana e culturalmente mais ampla, que não esteja apenas focada no trabalho dos aspectos teóricos, experimentais e tecnológicos dos conteúdos abordados.

As competências gerais dos PCN + de Física para o ensino médio destacam a importância de o aluno "compreender o conhecimento científico e o tecnológico como resultados de uma construção humana, inseridos em um processo histórico e social"5; soma-se a elas o fato de muitos pesquisadores das áreas de História, Filosofia e Ensino de Ciências ${ }^{6}$ ressaltarem a relevância de se desenvolver um trabalho consistente nesse sentido, ainda que não poucos sejam os obstáculos que se interpõem a tal tentativa de aproximação, principalmente no tocante à instância da formação dos futuros docentes.

Em um levantamento realizado junto a três grupos distintos de sujeitos frequentadores de cursos de nível superior voltados à formação de professores, André Ferrer Pinto Martins identificou alguns desses principais obstáculos, dentre os quais se destacam:

- A pouca disponibilidade de material didático de qualidade, ainda que nos últimos anos a tendência tenha sido de significativo aumento da oferta;

- Uma demasiada preocupação das escolas em preparar seus alunos para exames vestibulares, dos quais os conteúdos de História e Filosofia da Ciência (HFC) estão ausentes;

- Dificuldade e resistência do aluno do ensino médio em perceber a relevância da HFC em seu aprendizado, reforçadas pelo descarte deliberado desse corpo de conhecimentos dos exames vestibulares;

- A relutância dos docentes de Física, e das Ciências da Natureza em geral, no sentido de perceberem que 0 fracasso de iniciativas do uso da HFC em sala de aula também está relacionado aos próprios professores, e não somente a questões externas (livros, vestibulares, alunos etc.); e

- As disciplinas que trabalham HFC nos cursos de formação inicial de professores sem efetividade, considerando-se que os licenciandos raramente incorporam as ações desenvolvidas nesses cursos em suas práticas pedagógicas. ${ }^{?}$

Sem a pretensão ingênua de oferecer uma solução definitiva para a superação de tantos obstáculos, o foco da nossa pesquisa concentrou-se na instância da formação dos futuros docentes, visto que muitos deles comumente atribuem significativo valor à História da Ciência enquanto estratégia didático-pedagógica sem, contudo, conseguirem efetivar o uso dos principais critérios norteadores desse campo de conhecimentos como parte integrante de suas futuras ações didáticas. 
Assim sendo, buscamos oferecer uma contribuição pontual para se viabilizar essa aproximação, que culminou na proposição de uma sequência de ensino contemplando um determinado conteúdo de FMC, apoiada sobre uma abordagem norteada por alguns dos critérios da chamada "moderna", ou "contemporânea", historiografia da ciência. Também utilizamos um breve questionário de pesquisa, que foi respondido por um grupo de licenciandos, visando à caracterização dos seus conhecimentos prévios em relação à temática abordada. As informações assim coletadas contribuíram para avaliar o mérito da intervenção promovida.

\section{A moderna historiografia da ciência e suas interlocuções com o ensino}

A aproximação entre a história da ciência e o ensino de ciências tem sido defendida, há muito tempo, não apenas no sentido de promover a aprendizagem de conceitos mas, também, daquilo que se convencionou denominar Natureza da Ciência $(\mathrm{NdC})^{8}$.

Ainda que não se pretenda que os estudantes da educação básica, ou mesmo seus professores, dominem concepções sobre a ciência tão elaboradas e complexas quanto aquelas discutidas por filósofos, historiadores e sociólogos da ciência, é desejável que os estudantes desenvolvam uma visão menos ingênua, que contemple, ao menos em parte, a complexidade do empreendimento científico ${ }^{9}$. Alguns autores procuraram sistematizar o que seria uma "visão consensual" a respeito da $\mathrm{NdC}$, reunindo, em uma série de tópicos, os aspectos a serem ensinados ${ }^{10}$. Outros autores, porém, criticaram essa "visão consensual", apontando restrições de natureza filosófica, educacional e, também, a incompletude dessa caracterização"11.

Entre os aspectos da NdC mais destacados pelos educadores em ciência que se dedicam a investigar seu efetivo ensino encontra-se a "influência mútua entre o contexto sociocultural e o conhecimento científico que é produzido"12 - 0 que é de particular interesse para a abordagem que é proposta no presente trabalho.

Embora diversos autores, como Michael Matthews, tenham apontado para a necessidade de se discutir detalhes que mostrem a complexidade do processo de construção da ciência' ${ }^{13}$, parece haver uma omissão importante nos trabalhos produzidos por educadores em ciência: a necessidade de discussões de caráter historiográfico ${ }^{14}$. É certo que Douglas Allchin chama a atenção para questões historiográficas, denunciando o que denomina de "pseudo-história", ao ressaltar que muitas vezes os textos produzidos por educadores em ciências resultam em distorções da história da ciência, como considerar os trabalhos de cientistas do passado ou como verdades triunfantes, ou como erros patológicos ${ }^{15}$. Abordagens como essas resultariam em ideias inadequadas sobre a construção da ciência, sendo, portanto, prejudiciais ao ensino de ciências. Allchin acredita que não seria difícil os professores de ciências reconhecerem e evitarem esse tipo de relato, bastando para isso estarem atentos a uma série de características, que o autor chama de "sinais de alarme para a pseudo-história"16. Matthews, por sua vez, considera que distorções da história da ciência nos textos didáticos são "inevitáveis"17. Entretanto, para esse autor, isso não seria um problema, considerando que os objetivos e métodos dos historiadores da ciência e dos educadores em ciência são bastante distintos: para os educadores, não importaria que a história fosse distorcida, desde que cumprisse sua finalidade didática. ${ }^{18}$

Discordamos das posturas tanto de Matthews, quanto de Allchin. Acreditamos que os educadores podem se beneficiar do conhecimento produzido pelos historiadores da ciência, elaborando trabalhos que abordem a história de maneira simplificada sem que isso, entretanto, signifique inadequações historiográficas. Além disso, não acreditamos que o uso de rótulos como "pseudo-história" contribua positivamente para o debate. 0 educador em ciências que for pouco versado em história da ciência pode acreditar que esse rótulo negativo é atribuído por autores a narrativas históricas que simplesmente não lhes agradem, sem compreender as razões de sua inadequação. Nesse caso, a estratégia mais adequada seria introduzir explicitamente as questões historiográficas nos cursos de formação inicial e continuada de professores de ciências, oferecendo oportunidades para reflexões a respeito da historiografia da ciência. Tais reflexões precisam incluir as transformações que a própria historiografia da ciência sofreu ao longo do tempo ${ }^{19}$. 
Assim procedendo, o educador em ciências poderia compreender que, até meados do século XX, houve o predomínio de uma concepção linear e acumulativa da história da ciência, que destacava o papel de experimentos cruciais e de considerações teóricas. Como se acreditava que a ciência era um processo de descoberta das "verdades" gradativamente reveladas pela Natureza, a história da ciência era progressiva e triunfante, conduzindo necessariamente à ciência atual. Isso significa que uma narrativa produzida sob tal viés historiográfico não constitui uma pseudo-história, mas apenas uma abordagem hoje considerada superada.

A contemporânea historiografia da ciência reconhece a importância do contexto social na construção da ciência; a ocorrência de rupturas no processo de construção do conhecimento científico; as contribuições de outras formas de conhecimento (como a magia, os ofícios práticos, a astrologia, os saberes populares etc.) e de outros povos e culturas além dos europeus, em diferentes épocas; e busca compreender as ideias científicas do passado no contexto em que foram produzidas, e não como "antecipações" ou "precursoras" das ideias do presente. Deve-se considerar que, ao descartar determinadas abordagens historiográficas como pseudo-história, está-se sujeito a incorrer no mesmo tipo de anacronismo que se critica nos relatos de história da ciência das primeiras décadas do século passado, ou seja, cobrar que a historiografia antiga usasse critérios que só foram desenvolvidos posteriormente.

0 impacto das mudanças na historiografia da ciência sobre o ensino de ciências já fora reconhecido por Stephen Brush, na década de 1970:

[...] o professor que deseja doutrinar seus alunos no papel tradicional do cientista como um descobridor neutro dos fatos não deve usar materiais históricos do tipo que agora vêm sendo produzidos pelos historiadores da ciência: eles não servirão a seus propósitos. [...] Por outro lado, aqueles professores que desejarem contrabalançar o dogmatismo dos livros didáticos e fornecer alguma compreensão da ciência como uma atividade que não pode ser separada de considerações metafísicas ou estéticas podem encontrar algum estímulo na nova história da ciência. ${ }^{20}$

Tendo isso em vista, consideramos que, ao ser apresentado ao processo histórico da própria historiografia da ciência, o professor de ciências terá melhores condições de compreender o que há por trás de diferentes relatos históricos, e poderá escolher criticamente as abordagens mais condizentes com seus próprios objetivos educacionais. A não compreensão dos diferentes critérios que orientam a produção de narrativas históricas pode fazer com que um professor faça uso de um texto cujas entrelinhas "sugerem uma visão de ciência diferente daquela que se busca defender" ${ }^{21}$

Considerando, portanto, a complexidade intrínseca a toda tentativa de se utilizar a história da ciência como estratégia de didático-pedagógica, detalhamos a seguir uma intervenção pautada por tal sinergia, realizada em um curso regular de formação de professores.

\section{O ensino de física nuclear na instituição de ensino superior escolhida}

Dentro do conjunto de conteúdos de FMC, optamos neste trabalho por abordar especificamente a Física Nuclear, dado o seu potencial para discutir questões de relevância social e histórica no mundo contemporâneo. Trata-se de um tema que ocupa grande destaque na mídia, uma vez que o uso da energia nuclear, especialmente para geração de energia elétrica, está na pauta dos grandes debates do momento, no Brasil e no mundo, envolvendo aspectos científicos, tecnológicos, econômicos, sociais, históricos e ambientais.

Por se tratar de um assunto sempre atual - e, em muitos aspectos, polêmico e controverso -, sua inserção na escola média é essencial, e possibilita que os alunos lidem com informações veiculadas pela mídia, desenvolvendo habilidades para compreenderem, questionarem e se posicionarem criticamente quanto a eventuais debates surgidos nesse contexto. 0 alarido provocado pelo acidente ocorrido em 2011 nas usinas nucleares da cidade japonesa de Fukushima é um exemplo da repercussão dessa temática. 
Nos cursos de formação inicial de professores de física oferecidos pelas instituições brasileiras de nível superior, disciplinas contemplando conteúdos de FMC são obrigatórias. Visando caracterizar os conhecimentos preliminares de licenciandos em física acerca do histórico do uso da energia nuclear - para posteriormente avaliar impactos de uma intervenção - escolhemos um grupo de alunos do campus São Paulo do Instituto Federal de Educação, Ciência e Tecnologia de São Paulo (IFSP-SP) como foco dessa instância do nosso trabalho. Nessa instituição, o curso tem duração ideal de oito semestres e forma professores de Física desde 2005, ano de colação de grau da primeira turma.

Na matriz curricular do curso encontramos duas disciplinas semestrais que abordam a FMC, comprometidas em suas ementas com o formalismo teórico e experimental da Física Nuclear, e que fazem alusão à história e à promoção de discussões éticas e filosóficas no entorno desse corpo de conhecimentos. São elas: Física Atômica e Molecular (FAM), oferecida no $6^{0}$ semestre, e Física Nuclear e de Partículas (FNP), oferecida no $7^{0}$ semestre. Cabe destacar que outros conteúdos de FMC, não relacionados diretamente com a Física Nuclear, são trabalhados por outras disciplinas, distribuídas entre $05^{0}$ e $07^{0}$ semestres.

Ainda no $6^{0}$ semestre, é oferecida uma disciplina obrigatória denominada Ciência, História e Cultura (CHC). Sua ementa declara que tal espaço curricular

aborda não apenas elementos da historiografia da ciência, mas problematiza o seu papel no ensino e na divulgação científica. São estudados materiais didáticos, produção acadêmica e projetos de ensino que incorporam e propõem o ensino da física articulado à dimensão cultural da ciência e as relações múltiplas entre a implicação e a determinação social do conhecimento científico e seus produtos tecnológicos. Aos alunos, são propostas atividades de estudo visando à incorporação da pesquisa em ensino da física à prática de sala de aula. ${ }^{22}$

A ampla abrangência desse texto permite ao docente responsável pela disciplina dar ênfase, por exemplo, às

possibilidades de aproximação entre a História da Ciência e o Ensino de Física. Entre a preocupação em apresentar e desenvolver aspectos próprios da historiografia da ciência e as questões norteadoras do trabalho com a didática da ciência, discussões abarcando aspectos próprios da NdC permeiam o curso, sendo destacadas e aprofundadas em cada episódio trabalhado ao longo das aulas.

Destacamos na próxima seção as respostas oferecidas pelos licenciandos a um questionário que lhes foi apresentado e, também, os principais detalhes de uma intervenção feita junto ao grupo de alunos inscritos nessa disciplina no primeiro semestre letivo de 2012, na forma de uma sequência de ensino destinada à apresentação do histórico da energia nuclear, em nível mundial e nacional.

\section{Uma abordagem didática para o histórico da energia nuclear proposta em conjunto com um questionário investigativo}

Desenvolvida em sala de aula ao longo de 7 horas-aula de 45 minutos cada, nossa intervenção procurou ampliar 0 alcance e a qualidade dos conhecimentos teóricos, experimentais e tecnológicos já assimilados pelos licenciandos sobre a física e a energia nucleares, oferecendo-Ihes a possibilidade de se aprofundarem no estudo dos aspectos metacientíficos associados ao modus operandi da ciência.

Inicialmente, apresentamos o documentário Projeto Manhattan ${ }^{23}$, da série Maravilhas Modernas, produzido em 2002 pelo canal de TV norte-americano The History Channel, cujo foco principal são as justificativas dos construtores das bombas atômicas para seu uso contra duas cidades japonesas, no ano de 1945, eventos que marcaram o final da Segunda Guerra Mundial. Temos aqui o ponto de vista e as justificativas dos "vencedores da guerra". 
Exibimos, em seguida, outro documentário, denominado Luz branca, chuva negra: A destruição de Hiroshima e Nagasaki ${ }^{24}$, produzido em 2007 pela também norte-americana HBO Documentary Films. Dirigido pelo nipo-americano Steven Okazaki, o filme expõe a outra face da moeda, apresentando os relatos de cerca de duas dezenas de sobreviventes dos bombardeios nucleares, além de outros detalhes a respeito do Projeto Manhattan que não constam do documentário do The History Channel.

0 principal objetivo de se utilizar esses documentários concentra-se em apresentar, em um estudo de caso, as visões, motivações e versões dos diversos atores de um episódio histórico de imensa magnitude - 0 qual, geralmente, é levado para a opinião pública de forma simplificada e distorcida, oferecendo pouca ou nenhuma margem para a formação e a atuação de cidadãos críticos capazes de ler, nas entrelinhas, intencionalidades e consequências das ações de tais personagens.

Em outra atividade, tendo como principal objetivo identificar os conhecimentos preliminares dos alunos a respeito de aspectos da história da utilização da energia nuclear no Brasil, indicamos a leitura de trechos de uma dissertação de mestrado ${ }^{25}$ apresentando uma cronologia dos acontecimentos relacionados Programa para Formação de Profissionais da Área Nuclear no Brasil (Pronuclear), relacionando seu insucesso ao surgimento do Programa Nuclear Paralelo (PNP). Para aprofundar a apresentação do PNP aos alunos, exibimos a eles o documentário em vídeo Programa Nuclear da Marinha e seus desafios ${ }^{26}$, produzido em 1994 pela TV Globo, e apresentado no mesmo ano no programa Globo Ciência.

Essa instância do trabalho visava caracterizar o que, de fato, os licenciandos conheciam acerca da ciência feita no Brasil - a chamada Ciência Nacional - pois, aparentemente, seguimos reproduzindo um modelo de educação científica pautado pela predominante valorização da ciência feita e praticada somente pelas "grandes nações", visto que raras são as disciplinas de um curso de ciência que efetivamente apresentam e descrevem as incursões de personagens nacionais no empreendimento científico. Dessa maneira, se busca oferecer elementos essenciais para a constituição de uma consciência crítica a respeito do potencial dos trabalhos em ciência realizados em nosso país junto aos futuros professores de física - os quais, por sua vez, podem se sentir mais aptos para divulgar essa realidade em suas aulas na escola básica.

Cabe destacar que nossa opção por utilizar os vídeos foi uma alternativa adotada visando contornar a pequena oferta de material didático como suporte às aulas acerca dessa temática, principalmente quando buscamos recursos que discutem e explicitam as questões sócio-políticas relacionadas ao histórico da energia nuclear, viabilizando abordagens e problematizações que privilegiem uma dimensão cultural mais ampla.

Em relação à física nuclear e à energia nuclear, como destacado anteriormente, havia a preocupação com os conhecimentos dos licenciandos a respeito de alguns episódios históricos relacionados a essas temáticas, bem como suas opiniões acerca de escolha da energia nuclear como alternativa para composição da matriz energética brasileira. Com esse intuito, um breve questionário foi proposto aos alunos no ambiente virtual Moodle do IFSP-SP, após o desenvolvimento completo da sequência didática trabalhada em sala de aula. Havia 19 alunos matriculados que frequentavam a disciplina, dos quais 15 responderam às seguintes questões:

1) 0 que você já conhecia a respeito do Projeto Manhattan?

2) Quais detalhes envolvendo o histórico da energia nuclear no Brasil já eram do seu conhecimento?

3) Em sua opinião, o que justifica o fato de os americanos terem lançado as duas bombas nas cidades japonesas de Hiroshima e Nagasaki, mesmo após o então poderio militar japonês ter sido praticamente dizimado?

4) Qual sua opinião sobre o fato de o Brasil ter demorado três décadas para se tornar signatário do Tratado de Não Proliferação de Armas Nucleares, proposto originalmente no ano de 1968?

5) Quais dos principais aspectos ligados à NdC você identifica mais claramente presentes no histórico da energia nuclear trabalhado nesta disciplina?

6) De forma sucinta, posicione-se em relação ao uso da energia nuclear no Brasil (se vale a pena, ou não, e por que). 
Para além da simples constatação do provável desconhecimento dos alunos em relação aos detalhes inquiridos, as questões 1 e 2 - apresentadas somente após concluída toda a intervenção - tinham como objetivo a conscientização dos licenciandos acerca da importância do assunto abordado, bem como lhes permitia avaliar a extensão dessa lacuna em sua formação docente.

As questões 3 e 4 procuravam verificar a efetividade das informações discutidas na sequência de ensino, exigindo dos licenciandos respostas caracterizadoras de sua compreensão sobre fatos relacionados aos incidentes ocorridos durante e após a execução do Projeto Manhattan, bem como suas consequências. Dentre elas, destaca-se a forma pela qual as diversas nações do mundo - em especial, o Brasil - foram afetadas pelas ações que visaram garantir a primazia do trabalho com a tecnologia nuclear aos países que têm assento permanente no Conselho de Segurança da ONU. Nesse sentido, possibilitou-se aos alunos refletir sobre as ações desses países em episódios mais recentes, como a invasão do Iraque no ano de 2003, por exemplo.

A questão 5 procurou exercitar o olhar dos licenciandos acerca de alguns aspectos selecionados da natureza da ciência previamente debatidos em sala de aula. As discussões a respeito de esses aspectos serem, ou não, "consensuais" - realizadas em momentos anteriores do curso -, ganharam novo fôlego e novos matizes, refletidos nas respostas oferecidas pelos alunos.

Por fim, a questão 6 se concentrou em avaliar a capacidade dos licenciandos fazerem juízo de valor sobre uma questão que voltou à ordem do dia - a partir de novos contornos - após o acidente ocorrido em 2011 na usina termonuclear de Fukushima, no Japão: a pertinência da opção pelo uso da energia nuclear no Brasil. Vale lembrar que a retomada da construção da usina de Angra 3 tem sido objeto de discussão em diversos setores da nossa sociedade, o qual poderia estar presente também na escola básica, por intermédio dos professores de ciências.

As respostas dadas pelos alunos encontram-se sumarizadas na tabela 1. Os números entre parênteses indicam a quantidade de alunos que deram determinada resposta. Para a $5^{a}$ questão, a soma das respostas supera a quantidade de participantes, pois mais de um aspecto poderia ser destacado pelos alunos.

Tabela 1 Síntese das respostas dadas pelos alunos às questões

\begin{tabular}{|c|c|}
\hline Questão & Respostas \\
\hline 1 & $\begin{array}{l}\text { Desconheciam totalmente (9); Foi um projeto norte-americano destinado à construção de armas nucleares (5); } \\
\text { Foi um projeto norte-americano destinado à construção de armas nucleares, com a participação de cientistas } \\
\text { de renome (1). }\end{array}$ \\
\hline 2 & $\begin{array}{l}\text { Nenhum detalhe (12); Ocorreu um acidente com material radioativo na cidade de Goiânia em } 1987 \text { (2); Brasil } \\
\text { e Alemanha Ocidental assinaram um acordo nos anos } 1970 \text { visando à construção de usinas nucleares (1). }\end{array}$ \\
\hline 3 & $\begin{array}{l}\text { Demonstrar ao Japão e às demais nações do mundo sua supremacia militar (9); Retaliação ao ataque japonês } \\
\text { feito a Pearl Harbor, em } 1941 \text { (2); Não responderam (4). }\end{array}$ \\
\hline 4 & $\begin{array}{l}\text { Conquistar autônoma e secretamente o conhecimento da tecnologia nuclear (6); Fazer o jogo das nações } \\
\text { desenvolvidas (2); Desinteresse do país em opinar em questões envolvendo a energia nuclear (1); Não res- } \\
\text { ponderam (6). }\end{array}$ \\
\hline 5 & $\begin{array}{l}\text { Ideias científicas são influenciadas pelo contexto social e histórico (11); A ciência é parte das tradições culturais } \\
\text { e sociais (4); } 0 \text { conhecimento científico apóia-se fortemente, mas não inteiramente, em observações, evidências } \\
\text { experimentais, argumentos racionais e no ceticismo (3); A ciência é uma tentativa de se explicar fenômenos } \\
\text { naturais (2); A História da Ciência revela tanto um caráter evolucionário quanto revolucionário (2). }\end{array}$ \\
\hline \multirow{2}{*}{6} & $\begin{array}{l}\text { A favor: - Para diversificar a matriz energética (6); Por se tratar de uma "energia limpa" (2); Para justificar todo } \\
\text { investimento previamente feito (1); Para promover desenvolvimento tecnológico (1). }\end{array}$ \\
\hline & $\begin{array}{l}\text { Contra: Falta de destino seguro para o "lixo radioativo" (2); Receio do potencial bélico (1); Risco de acidentes } \\
\text { (1); Elevado custo financeiro e social (1). }\end{array}$ \\
\hline
\end{tabular}


Analisando as respostas dadas para as questões 1 e 2, pode-se observar que, em termos percentuais, um considerável contingente de professores em formação inicial declarou desconhecer o histórico envolvendo a energia nuclear. Há que se ressaltar que o universo amostral contempla alunos do $6^{0}$ semestre, que na sua absoluta maioria, já completaram mais de 70\% do curso de graduação. Esses dados sugerem a necessidade de se promover maior contextualização histórica dos conteúdos apresentados aos alunos de graduação, o que poderia auxiliá-los a compreender o papel dos físicos na sociedade. Em relação à energia nuclear no contexto brasileiro, a maioria dos alunos afirmou não conhecer nenhum detalhe sobre 0 assunto. As poucas menções foram ao trágico episódio de Goiânia, bastante comentado na mídia na época dos acontecimentos, e à existência de usinas nucleares na cidade fluminense de Angra dos Reis. Essas respostas demonstram que há muito a ser feito, no curso de licenciatura, no sentido de apresentar o Brasil como participante do cenário científico e tecnológico mundial, e de se contrapor à ideia de que a ciência e a tecnologia são produtos de alguns povos "privilegiados".

As respostas às questões 3 e 4 revelam que alguns licenciandos foram capazes de estabelecer algumas relações simples entre as informações de que dispunham ou que adquiriram durante a sequência didática. Por outro lado, chama a atenção o número de alunos que não responderam a essas questões, e algumas respostas ingênuas ou pouco relacionadas aos questionamentos. São resultados que indiciam as dificuldades dos licenciandos em lidar com uma perspectiva histórica da ciência, relacionando-a a contextos de épocas passadas, o que pode vir a se constituir em obstáculo, por exemplo, para a adoção de atividades interdisciplinares em sua futura ação docente.

Em contrapartida, as respostas dadas para as questões 5 e 6 forneceram alguns indícios animadores. Para essas questões, os alunos deixaram entrever uma potencial capacidade de perceber a ciência atual inserida em uma dimensão sócio-político-cultural, defendendo seus posicionamentos acerca dos possíveis rumos a serem tomados por políticas de Estado de cunho científico. Ainda que os questionários ofereçam, em si, pouca margem para essa conclusão, as discussões ocorridas em aula corroboram tais indicativos, visto que muitos foram os alunos interessados em se posicionarem em relação aos questionamentos efetuados, mesmo aqueles que, ao longo do semestre, se mostraram em geral avessos a uma participação mais incisiva e eloquente.

Evidentemente, tais resultados devem ser relativizados, considerando o fato de a intervenção ter sido pontual, além do natural limite da amostra de sujeitos investigados nesta pesquisa. Entretanto, os resultados sugerem que a abordagem proposta neste trabalho, utilizando uma abordagem da História da Ciência na formação de professores de Física, tem potencial para permitir uma melhor compreensão desses sujeitos a respeito do funcionamento da ciência e de suas implicações no cotidiano da sociedade. Assim, possibilita-se ao professor assumir uma postura mais abrangente, crítica e assertiva ao abordar os conteúdos de Física em sua prática cotidiana.

\section{Considerações finais}

Episódios extremamente relevantes no processo histórico estudado - tais como o Projeto Manhattan, o programa Átomos para a Paz, a assinatura do Acordo Nuclear Brasil-Alemanha Ocidental e o Programa Nuclear Paralelo, dentre outros - não têm chegado às salas de aula, a despeito do imenso manancial de discussões que poderiam motivar, tanto em termos de contextualização do conhecimento físico, como a respeito da natureza da ciência.

Consideramos a omissão e a simplificação dos processos históricos que concorreram para a constituição de determinado ramo da ciência como abordagens que contribuem para a falta de interesse dos alunos em relação às questões referentes à essência dos trabalhos desenvolvidos em ciência. Por isso, as formas de se abordar a História da Ciência no contexto escolar devem merecer especial atenção na elaboração e revisão dos currículos dos cursos de formação de professores das universidades brasileiras.

A análise das respostas oferecidas pelos alunos às questões que lhes foram apresentadas no contexto desta investigação reforçou uma constatação conhecida por quem trabalha na formação dos futuros docentes: os licenciandos em 
Física, ainda que previamente familiarizados com aspectos teóricos, experimentais e tecnológicos envolvendo a física e a energia nucleares, pouco conhecem a respeito de seu desenvolvimento histórico em nível mundial e, mais claramente, nacional. Nesse sentido, os resultados aqui observados apontam para a necessidade de a contextualização histórica do conhecimento físico ser mais valorizada nas disciplinas da graduação, a fim de fornecer aos licenciandos um panorama mais completo (e mais complexo) a respeito dos significados da ciência e de suas relações com a sociedade.

Visando contribuir para preencher essa preocupante lacuna na formação dos professores de Física, a sequência de ensino descrita neste artigo - baseada em textos acadêmicos e documentários em vídeo -, buscou abordar, na forma de estudos de caso, diferentes pontos de vista dos diversos atores do cenário científico em episódios históricos selecionados. Tal enfoque mostrou-se relevante para identificar e promover reflexões sobre alguns aspectos da natureza da ciência junto aos professores em formação, oferecendo-Ihes informações acerca do funcionamento do empreendimento científico para além de seus notórios resultados tecnológicos, permitindo-lhes uma reflexão mais profunda sobre questões mais gerais - como, por exemplo, os usos da energia nuclear em termos de diversificação da matriz energética brasileira. 0 resultado dessa abordagem com os licenciandos sugere a possibilidade de se trabalhar essa temática, sob o viés aqui descrito, também com alunos do ensino médio.

Por conta das reflexões promovidas junto aos licenciandos, favorecendo a formação de opiniões mais críticas em relação à temática abordada, outra possibilidade para essa sequência de ensino - devidamente adaptada às contingências de cada contexto didático - recai em seu potencial para auxiliar a atualização dos conhecimentos de profissionais que já se encontram há tempos nas salas de aula, a respeito de temas pouco explorados, mas de reconhecida importância, no ensino da Física. Isso pode colaborar para que os professores estejam mais bem preparados para serem efetivos partícipes de uma educação promotora da formação de cidadãos verdadeiramente críticos acerca da ciência presente em seu cotidiano.

\section{Notas e referências bibliográficas}

Winston Gomes Schmiedecke é doutorando em Ensino de Ciências (Modalidade: Física) pela Universidade de São Paulo (USP), e professor efetivo do Instituto Federal de Educação, Ciência e Tecnologia de São Paulo (IFSP). E-mail: winston@usp.br.

Paulo Alves Porto é doutor na área de História da Ciência pela Pontifícia Universidade Católica de São Paulo (PUC-SP), livre docente em Ensino de Química pela Universidade de São Paulo (USP), e professor associado do Instituto de Química da USP. E-mail: palporto@iq.usp.br.

1 Agradecemos ao Conselho Nacional de Desenvolvimento Científico e Tecnológico (CNPq) pela concessão de bolsa de produtividade em pesquisa a um dos autores (PAA).

2 TERRAZZAN, Eduardo Adolfo. Perspectivas para inserção da Física Moderna na escola média. 1994. Tese (Doutorado) - Universidade de São Paulo; CAMARGO, Antonio José. A introdução de física moderna no segundo grau: obstáculos e possibilidades. 1996. Dissertação (Mestrado) - Universidade Federal de Santa Catarina; VALADARES, Eduardo de Campos; MOREIRA, Alysson Magalhães. Ensinando física moderna no segundo grau: efeito fotoelétrico, laser e emissão de corpo negro. Caderno Catarinense de Ensino de Física, v. 15, n. 2, p. 121-135, 1998; PINTO, Alexandre Custodio; ZANETIC, João. É possível levar a física quântica para o ensino médio? Caderno Brasileiro de Ensino de Física, v. 16, n. 1, p. 7-34, 1999; OSTERMANN, Fernanda; MOREIRA, Marco Antonio. Atualização do currículo de Física na escola de nível médio: um estudo desta problemática na perspectiva de uma experiência em sala de aula e da formação inicial de professores. In: ENCONTRO DE PESOUISA EM ENSINO DE FíSICA, 7., Atas... Florianópolis, 2000; BROCKINGTON, Guilherme; PIETROCOLA, Mauricio. Serão as regras da transposição aplicáveis aos conceitos de física moderna? In: ENCONTRO DE PESQUISA EM ENSINO DE FÍSICA, 6., Atas... Jaboticatubas, 2004.

3 BRASIL. Ministério da Educação. Orientações Educacionais Complementares aos Parâmetros Curriculares Nacionais (PCN+ - Ensino Médio). Brasília: MEC/SEB, 2002; BRASIL. Guia de livros didáticos: PNLD 2012 - Física. Brasília: MEC/SEB, 2011; BRASIL. Diretrizes curriculares nacionais para 0 ensino médio. Brasília: MEC/SEB, 2012.

4 BRASIL, op. cit., 2011, p.16.

5 BRASIL, op. cit., 2002, p.14.

6 GIL-PÉREZ, Daniel. Contribución de la Historia y de la Filosofía de las Ciencias al desarrollo de un modelo de enseñanza/aprendizaje como investigación. Enseñanza de las Ciencias, v. 11, n. 2, p. 197-212, 1993; MATTHEWS, Michael. História, filosofia e ensino de ciências: a tendência atual de reaproximação. Caderno Catarinense de Ensino de Física. Florianópolis, v.12, nº 3, p.164-214, 1995; PEDUZZI, Luiz Orlando de Quadro. Sobre a utilização didática da história da ciência. In: PIETROCOLA, Mauricio (org.) Ensino de Física: conteúdo, metodologia e epistemologia numa concepção integradora. Florianópolis: UFSC, 2001; MARTINS, Roberto de Andrade. A história das ciências e seus usos na educação. In: SILVA, Cibelle Celestino (org). Estudos de História e Filosofia 
das Ciências: subsídios para aplicação no ensino. São Paulo: Editora Livraria da Física, 2006. Introdução; PORTO, Paulo Alves. História e Filosofia da Ciência no Ensino de Química: em busca dos objetivos educacionais da atualidade. In: SANTOS, W. L. P.; MALDANER, O. A. (orgs.), Ensino de Química em Foco. ljuí: Editora Unijuí, p. 159-180, 2010; FORATO, Thaís Cyrino de Mello, MARTINS, Roberto de Andrade, PIETROCOLA, Mauricio. Historiografia e natureza da ciência em sala de aula. Caderno Brasileiro de Ensino de Física, v. 24, n. 1, p.112-131, 2011; HÖTTECKE, Dietmar; SILVA, Cibelle Celestino. Why Implementing History and Philosophy in School Science Education is a Challenge: An Analysis of Obstacles. Science \& Education, n. 20, p. 293316, 2011.

7 MARTINS, André Ferrer Pinto. História e filosofia da ciência no ensino: há muitas pedras nesse caminho. Caderno Brasileiro de Ensino de Física, v.24, n. 1, p.112-131, 2007.

8 LEDERMAN, Norm.; ABD-EL-KHALICK, Fouad.; BELL, Randy; SCHWARTZ, Renée. Views of nature of science questionnaire: towards valid and meaningful assessment of learners' conceptions of the nature of science. Journal of Research in Science Teaching, v. 39, p. 497-521, 2002.

9 MATTHEWS, Michael. In defense of modest goals for teaching about the nature of science. Journal of Research in Science Teaching, v. 35, p. 161-174, 1998.

10 LEDERMAN, op. cit., 2002, p. 501-502.

11 IRZIK, Gurol; NOLA, Robert. A family resemblance approach to the nature of science for science education. Science \& Education, n. 20, 591-607, 2011; MATTHEWS, Michael. Changing the focus: from nature of science (NOS) to features of science (FOS). In: KHINE, M. S. (ed.). Advances in nature of science research. Dordrecht: Springer, p. 3-26, 2012.

12 LEDERMAN, op. cit., 2002, p. 501-502.

13 MATTHEWS, op. cit., 2012, p. 15-17.

14 PORTO, op. cit., 2010, p. 161.

15 ALLCHIN, Douglas. How not to teach history in science. The Pantaneto Forum, n. 7, 2002.

16 ALLCHIN, op. cit., 2002.

17 MATTHEWS, Michael. Science teaching: the role of history and philosophy of science. New York: Routledge, 1994.

18 MATTHEWS, op. cit., 1994, p. 200-201.

19 ALFONSO-GOLDFARB, Ana Maria; FERRAZ Marcia Helena; BELTRAN Maria Helena Roxo. A historiografia contemporânea e as ciências da matéria: uma longa rota cheia de percalços. In: ALFONSO-GOLDFARB, A. M.; BELTRAN M. H. R. (orgs.). Escrevendo a história da ciência: tendências, propostas e discussões historiográficas. São Paulo: EDUC; Livraria Editora da Física; Fapesp, p. 49-73, 2004; DEBUS, Allen. Ciência e história: o nascimento de uma nova área. In: ALFONSO-GOLDFARB, A. M.; BELTRAN M. H. R. (orgs.). Escrevendo a história da ciência: tendências, propostas e discussões historiográficas. São Paulo: EDUC; Livraria Editora da Física; Fapesp, p. 13-39, 2004; KRAGH, Helge. An introduction to the historiography of science. Cambridge: Cambridge University Press, 1987.

20 BRUSH, Stephen. Should the history of science be rated X?. Science, n. 183, p. 1170-1171, 1974. (Tradução nossa).

21 FORATO, Thaís. Cyrino de Mello; PIETROCOLA, Maurício; MARTINS, Roberto de Andrade. Historiografia e natureza da ciência na sala de aula. Caderno Brasileiro de Ensino de Física, v. 28, n. 1, p. 36, 2011.

22 Disponível em: <http://www.cefetsp.br/edu/lif/ementas.htm>. Acesso: 27 maio 2012.

23 HISTORY CHANNEL. Manhattan Project: Modern Marvels, ep. 21, temp. 9, 2002. Disponível em: <http://www.youtube.com/watch?v=v9pYDa6U-Fo > Acesso: 22 maio 2012.

24 HBO DOCUMENTARY FILM. White light, black rain: The destruction of Hiroshima and Nagasaki. 2007. Disponível em: <http://www.youtube.com/ watch?v=--p1ZVMOUjw > . Acesso: 22 maio 2012.

25 SCHMIEDECKE, Winston Gomes. 0 papel do Pronuclear (1976 - 1986) na formação de recursos humanos para a área nuclear no Brasil. 2006. Dissertação (Mestrado) - Pontifícia Universidade Católica de São Paulo.

26 TV GLOBO. GLOBO CIÊNCIA. Programa Nuclear da Marinha do Brasil e seus desafios. 1994. Disponível em: <http://www.youtube.com/ watch?feature $=$ player_embedded\&v $=$ GCXAo8vCqL0> . Acesso: 22 maio 2012.

[Recebido em Dezembro de 2013. Aprovado para publicação em Setembro de 2014]. 